\title{
Biological Allergy Unit per Milliliter
}

National Cancer Institute

\section{Source}

National Cancer Institute. Biological Allergy Unit per Milliliter. NCI Thesaurus. Code

C116231.

A unit of allergenic product potency expressed as a number of biological units per one milliliter of formulation. 